\title{
GRAU DE INFILTRAÇÃO MARGINAL DE DUAS TÉCNICAS RESTAURADORAS COM CIMENTO DE IONÔMERO DE VIDRO EM MOLARES DECÍDUOS: ESTUDO COMPARATIVO “ IN VITRO”
}

\author{
MICROLEAKAGE BETWEEN TWO FILLING RESTORATIVE TECHNIQUES \\ USING GLASS IONOMER CEMENT IN PRIMARY MOLARS: \\ COMPARATIVE “IN VITRO” STUDY
}

\begin{abstract}
Paulo Floriani KRAMER
Doutor em Odontopediatria pela FO/USP, Coordenador do Programa de Pós-Graduação em Odontopediatria da ULBRA-Canoas,RS e Professor de Odontopediatria da ULBRA-Canoas,RS.
\end{abstract}

Luiz Antonio Gaieski PIRES

Professor de Materiais Dentários da ULBRA-Canoas,RS, e Mestre em Prótese Dental pela ULBRA-Canoas,RS.

Maximiano Ferreira TOVO

Doutor em Odontopediatria pela FOB/USP, Professor de Odontopediatria da ULBRA-Canoas,RS.

Tatiana Canever KERSTING

Especialista em Odontopediatria pela ULBRA-Canoas, RS.

Simone GUERRA

Cirurgiã-Dentista.

\begin{abstract}
$A$ técnica do condicionamento ácido e o desenvolvimento e aprimoramento de novos materiais restauradores com características adesivas têm levado a mudanças importantes nas concepções e nos princípios da dentística operatória e restauradora. O objetivo deste estudo foi avaliar a microinfiltração marginal em cavidades proximais de molares decíduos restaurados com cimento de ionômero de vidro modificado por resina (Vitremer, 3M) comparando duas diferentes técnicas: a técnica convencional (conforme recomendações do fabricante) e a técnica de hibridização (ácido fosfórico-37\% e sistema adesivo Scotchbond Multi-Uso, 3M ). Foram utilizados 20 molares decíduos hígidos, onde foram preparadas cavidades proximais. A amostra foi dividida aleatoriamente em 2 grupos. No grupo 1 foi utilizada a técnica convencional e no grupo 2 a técnica com condicionamento ácido e aplicação de sistema adesivo. Os dentes foram submetidos ao processo de ciclagem térmica, impermeabilizados, mantendo uma área de $2 \mathrm{~mm}^{2}$ na margem cervical da restauração e imersos em solução de azul de metileno a 0,5\%, por 72 horas. A seguir, foram seccionados e avaliados por um único examinador, que estabeleceu o grau de microinfiltração. Os dados obtidos revelaram que as duas técnicas utilizadas apresentaram microinfiltração marginal em diferentes graus, e que não houve diferença estatisticamente significante entre elas.
\end{abstract}

UNITERMOS: Dente decíduo; Cimentos de ionômero de vidro. 


\section{INTRODUÇÃO}

A técnica do condicionamento ácido e o desenvolvimento e aprimoramento de novos materiais restauradores com características adesivas têm levado a mudanças importantes nas concepções e nos princípios da dentística operatória e restauradora.

As resinas compostas, juntamente com os sistemas adesivos, vêm sofrendo constantes avanços, mas ainda apresentam alguns efeitos adversos que prejudicam seu sucesso clínico. A contração de polimerização e o coeficiente de expansão térmica linear da resina composta nem sempre são controlados pelo sistema de adesão, ocasionando fendas, por onde ocorre a microinfiltração marginal. Em decorrência destes fatos, pode ocorrer sensibilidade pós-operatória, manchamento marginal da restauração, cárie recorrente e necrose pulpar. ${ }^{2,14}$

Os cimentos de ionômero de vidro, desenvolvidos por Wilson e Kent em 1972, surgiram como materiais que apresentam melhorias na adaptação marginal devido à sua adesão química ao esmalte e dentina, além da ação cariostática pela liberação de flúor, biocompatibilidade e coeficiente de expansão térmica similar ao dente. Estes materiais se apresentam em forma de pó, basicamente um vidro de silicato de alumínio contendo fluoreto em alta concentração e um líquido, uma solução aquosa de ácido poliacrílico. ${ }^{4,12}$

Os cimentos convencionais apresentam algumas limitações mecânicas e clínicas, tais como o tempo de reação de geleificação prolongado, sensibilidade, desidratação ou excesso de umidade inicial, baixa resistência à tensão e compressão e problemas estéticos devido a sua translucidez limitada. Desta forma, novos materiais ionoméricos foram introduzidos no mercado melhorando, principalmente, as características de manipulação e estética, e mantendo suas principais propriedades. Foi sugerida, assim, a adição de partículas metálicas ao material para conferir melhores propriedades mecânicas. Como o resultado estético era bastante limitado, foram desenvolvidos os cimentos de ionômero de vidro modificados por resina, com componentes que polimerizam pela ação da luz e alguns componentes adicionais autopolimerizáveis. Estas modificações fizeram com que o material aumentasse sua resistência ao contato com a umidade e desidratação sofridas precocemente, melhorando também suas propriedades mecânicas e conferindo-lhes maior resistência, estabilidade de cor e durabilidade. ${ }^{1,3,9}$

A reação de presa ácido-base dos cimentos de ionômero de vidro modificados por resina é completada pela polimerização da resina, melhorando a adesão à dentina, que é causada por uniões químicas do componente do ácido poliacrílico e do componente resinoso (HEMA ou Bis-GMA). Por apresentarem uma boa adaptação marginal, promovendo melhor adesão aos tecidos dentais e superando algumas limitações dos cimentos de ionômero de vidro convencionais, podem ser indicados para procedimentos relacionados às áreas de odontopediatria, dentística, prótese, ortodontia e endodontia. ${ }^{1,13,4}$ Além disso, os preparos cavitários podem ser realizados apenas com a remoção do tecido cariado, mantendo maior quantidade de estrutura dental sadia. ${ }^{19}$ Estudos retrospectivos têm também demonstrado bons resultados clínicos do cimento de ionômero de vidro modificado por resina em restaurações de dentes decíduos. ${ }^{6}{ }^{12}$.

Observamos ainda uma evolução importante dos sistemas adesivos, que utilizados em associação à técnica de condicionamento ácido total, ou seja, em esmalte e dentina simultaneamente, formam a "camada híbrida", que segundo Nakabayashi, Kojima, Masuhara ${ }^{20}$ torna a superfície da dentina impermeável à penetração de bactérias, vedando a interface dente/ restauração. Além disto, possibilitam uma maior adesividade e eliminam ou minimizam a sensibilidade pós-operatória. ${ }^{5,14}$ Este aspecto é interessante pois os cimentos de ionômero de vidro resinosos também podem ser indicados em associação aos sistemas adesivos.

Diante de tal situação, e pelo fato do cimento de ionômero de vidro modificado por resina ter despontado como uma excelente alternativa restauradora, propomos avaliar "in vitro" o grau de infiltração marginal deste material seguindo-se às recomendações do fabricante e da técnica da hibridização de um sistema adesivo com condicionamento ácido.

\section{MATERIAL E MÉTODOS}

Foram selecionados em um banco de dentes do Curso de Odontologia da Universidade Luterana do Brasil-Canoas, RS, vinte molares decíduos hígidos que apresentavam, ao menos, um terço de raízes. Cada dente recebeu profilaxia com taça de borracha utilizando-se pedra-pomes e água. Os preparos cavitários foram executados em duas etapas. $\mathrm{Na}$ primeira, foi determinada a profundidade do preparo no sentido mésio-distal com ponta diamantada cilíndrica ${ }^{\circ} 1094$ (K.G. Sorensen). Na segunda etapa foi determinada a extensão vestíbulo-lingual com ponta diamantada cilíndrica ${ }^{\circ} 2094$ (K.G. Sorensen) 
em alta rotação com refrigeração. O limite cervical de todas as cavidades se estendeu até a junção amelocementária.

Para a confecção das matrizes foram utilizadas tiras metálicas de $5 \mathrm{~mm}$ de diâmetro que foram cortadas, brunidas, soldadas e adaptadas no limite cervical dos preparos com godiva de baixa fusão. Os dentes foram separados aleatoriamente em dois grupos e foram restaurados com cimento ionômero de vidro Vitremer $(3 \mathrm{M})$, utilizando-se duas técnicas restauradoras :

Grupo I (técnica convencional): Aplicação e polimerização do primer, segundo instruções do fabricante, inserção do cimento de ionômero de vidro na cavidade com o auxílio da seringa Centrix e polimerização por 40 segundos.

Grupo II (técnica com hibridização): Foi utilizado ácido fosfórico a $37 \%$ por 15 segundos no interior das cavidades, lavagem com água e secagem da cavidade, mantendo a dentina levemente úmida. Foi então utilizado o sistema adesivo Scotchbond Multi-Uso (3M), conforme instruções do fabricante. $\mathrm{O}$ adesivo foi aplicado com pincel e polimerizado por 10 segundos. Após a inserção do cimento de ionômero de vidro com a seringa Centrix procedeu-se a polimerização por 40 segundos.

Em ambos os grupos utilizou-se o aparelho XL1000 (3M), com uma intensidade de luz de $500 \mathrm{~mW} /$ $\mathrm{cm}^{2}$, medido por um radiômetro (Curing Radiometer Model 100, Demetron Co., USA). Após a remoção das matrizes metálicas foi realizado o acabamento das restaurações com tira de lixa na superfície proximal e pontas Enhance (Dentsply) na oclusal com posterior aplicação e polimerização do "finishing-gloss" .

A seguir, os dentes foram submetidos a 100 termociclos, composto cada um de 3 subciclos de $5^{\circ} \mathrm{C}$, $37^{\circ} \mathrm{C}$ e $55^{\circ} \mathrm{C}$, permanecendo em cada subciclo por 1 minuto, sendo que no intervalo entre as imersões de $5^{\circ} \mathrm{C}$ e $55^{\circ} \mathrm{C}$ eram novamente imersos em $37^{\circ} \mathrm{C}$.

Após a ciclagem térmica, os dentes tiveram os ápices, região de furca e eventuais áreas de reabsorção selados com ionômero de vidro fotopolimerizável (Vitremer, 3M) seguindo-se as orientações do fabricante, com a finalidade de evitar a penetração do corante por estas vias. Em seguida, os dentes foram impermeabilizados com uma camada de esmalte de unha e cera, deixando uma área de $2 \mathrm{~mm}^{2}$ na junção margem gengival-restauração .Na seqüência, os dentes foram imersos em solução de azul de metileno $0,5 \%$ (Multilab Ind. de Produtos Farmacêuticos Ltda) por 72 horas em uma estufa a $37^{\circ} \mathrm{C}$. Na etapa seguinte, os dentes foram retirados do corante, lavados em água corrente e removidas as camadas de cera e esmalte.

Os dentes foram seccionados no sentido mésiodistal no ponto médio da restauração com disco diamantado de face dupla (KG. Sorensen) montado em peça de mão. Já separados aos pares, os dentes passaram por uma avaliação através de microscopia ótica $(50 \mathrm{x})$.

O seguinte critério de avaliação foi seguido pelo examinador para identificar o grau de penetração do corante na interface dente-restauração, baseado em YAP, LIM, NEO ${ }^{28}$ : Grau 0: nenhuma infiltração; Grau 1: até a metade da parede gengival; Grau 2: toda parede gengival; e Grau 3: alcançando a parede axial.

Os resultados foram avaliados estatisticamente pelo teste não paramétrico Mann-Whitney .

\section{RESULTADOS}

Os graus de infiltração marginal, de acordo com a penetração do corante, atribuídos pelo examinador às duas técnicas restauradoras (convencional e com hibridização), estão descritos na Tabela 1.

Considerando-se os valores acima citados, podese afirmar que houve presença de maiores graus de infiltração nos dentes submetidos à técnica convencional (Tabela 1). Aplicando-se o teste nãoparamétrico de Mann-Whitney constatou-se, contudo, que não houve diferença estatisticamente significativa entre os grupos $(\mathrm{p}=0,149)$.

TABELA 1- Graus de infiltração marginal, de acordo com a penetração do corante, na técnica convencional e com hibridização

$\begin{array}{lll}\text { Grau de infiltração } & \text { Técnica Convencional } & \text { Técnica com Hibridização }\end{array}$

0

1

2

3

Total

$$
\begin{aligned}
& 12(60 \%) \\
& 2(10 \%) \\
& 2(10 \%) \\
& 4(20 \%) \\
& 20(100 \%)
\end{aligned}
$$
$17(85 \%)$
$2(10 \%)$
$0(0 \%)$
1 (5\%)
$20(100 \%)$ 


\section{DISCUSSÃO}

A microinfiltração pode induzir à pigmentação, sensibilidade pós-operatória e reincidência de cárie pela infiltração de microorganismos através da interface dente-restauração, tanto sob restaurações diretas quanto indiretas. ${ }^{2}$ A utilização do teste de microinfiltração pode ser a forma mais útil para avaliação de comparação dos materiais pois se baseia na indução de sucessivos estresses térmicos a fim de avaliar o potencial de adaptação de um material restaurador a estrutura dental. Desta forma, este teste simula laboratorialmente as condições ambientais que os materiais restauradores sofrerão quando aplicados clinicamente. Contudo, há uma grande variação na metodologia empregada, o que dificulta comparações entre os resultados obtidos..$^{15}$ Conforme os resultados obtidos em nosso estudo, não houve diferença estatisticamente significante entre as duas técnicas. Além disto, embora a técnica com hibridização tenha apresentado menores índices de infiltração marginal, nenhuma delas foi capaz de eliminar totalmente a microinfiltração. Resultados similares também foram encontrados por Rino, et al. ${ }^{21}$; Dias, et al. ${ }^{7}$; Silveira, et al. ${ }^{24}$ e Rodrigues ${ }^{22}$,em estudos in vitro. Resultado semelhante em avaliação in vivo foi também encontrado por Louguercio, et al. ${ }^{17}$

$\mathrm{Na}$ técnica convencional, $60 \%$ das restaurações apresentaram grau zero de infiltração. Este resultado pode ser atribuído a adesão do ionômero de vidro a estrutura dentária que ocorre em função do dente ser umedecido pelo líquido (ácido poliacrílico) e íons de hidrogênio reagirem com a superfície mineralizada, deslocando íons cálcio e fosfato, que reagem com grupos carboxílicos promovendo uma verdadeira união química entre o material restaurador e o dente. ${ }^{4}$

Sabendo que a capacidade de selamento de qualquer material é sempre crítica, vários aspectos contribuem para que os cimentos de ionômero de vidro possuam melhor qualidade de selamento marginal quando comparados com as resinas. ${ }^{23}$ Segundo Feilzer et al. ${ }^{10}$, apesar de apresentarem menor resistência adesiva, os cimentos de ionômero de vidro sofrem menor estresse e resultam em menor formação de fendas nas margens, como conseqüência da contração de polimerização, expansão e contração térmica. Os cimentos de ionômero de vidro apresentam o coeficiente de expansão térmica mais próximo ao da estrutura dentária e isso faz com que sejam alterados dimensionalmente de maneira semelhante a estrutura do dente, gerando menos tensões na interface ${ }^{12,13}$.

Quando índices de infiltração marginal são comparados, é quase uma rotina os cimentos de ionômero de vidro apresentarem infiltração marginal similar ou ainda menor que os sistemas resinosos ${ }^{25}$. Levando-se em consideração a umidade do substrato dentinário, os cimentos de ionômero de vidro são aparentemente menos sensíveis à esta, oferecendo valores semelhantes de adesão em diferentes graus de permeabilidade e umidade dentinária. Esses aspectos fazem com que os cimentos de ionômero de vidro apresentem um ótimo selamento marginal a curto e longo prazo, a despeito de sua resistência adesiva à dentina ser inferior àquela conseguida com os sistemas adesivos resinosos. ${ }^{3}$ Porém, neste trabalho, verificamos que nem sempre esta adesão impede a microinfiltração em restaurações realizadas com a técnica convencional, o que está de acordo com os achados de Leal ${ }^{16}$; Rino, et al. ${ }^{21}$; Dias, et al. ${ }^{7}$ e Fritscher, et al. ${ }^{11}$

De acordo com os resultados, $20 \%$ das restaurações apresentaram grau 3 de infiltração. Essa infiltração ocorre principalmente na junção amelocementária da caixa proximal, que são áreas mais críticas nas restaurações classe II com cimento de ionômero de vidro. Na técnica convencional, segundo o fabricante, não é recomendada a remoção da "smear layer", e isto, segundo, Swift Jr., Vann Jr. ${ }^{26}$, pode ser um dos fatores responsáveis pela infiltração marginal, pois apesar da "smear layer" agir como barreira de difusão que diminui a permeabilidade da dentina, ela também pode ser considerada um obstáculo a adesão dos materiais dentários à dentina, e ainda pode servir como um depósito de microorganismos e seus produtos.

Quando da utilização da técnica com hibridização, $85 \%$ das restaurações apresentaram grau zero de infiltração. Para Erickson ${ }^{8}$, esta menor infiltração é justificada pela utilização de sistemas adesivos que removem a "smear layer" com um ácido e expõem a superfície dentinária, permitindo a união química à dentina por meio de um adesivo hidrofílico, embricamento mecânico aos túbulos dentinários e micromecânico às fibras colágenas.

Na mesma técnica foi observado que apenas 5\% das restaurações apresentaram grau 3 de infiltração. Provavelmente o que justifica tal fato é a falta de habilidade do profissional na manipulação do material restaurador, ou ainda dificuldades técnicas. Para Miranda Jr. ${ }^{18}$, a microinfiltração pode ocorrer através de fendas marginais promovidas por todos os tipos de adesivos dentinários, e sempre haverá um espaço microscópico entre a restauração e as paredes da cavidade.

No presente estudo foi observado que nenhuma das técnicas avaliadas evitaram a presença da microinfiltração na interface dente-restauração, 
demonstrando que apesar das propriedades dos cimentos de ionômero de vidro modificados por resina e da utilização de sistema adesivo, estes não foram capazes de promover o selamento ideal das interfaces, predominando um padrão de infiltração discreto. Testes de avaliação in vitro são de grande valia como parâmetros para a utilização clínica destas técnicas, mas não podem ser extrapolados de maneira direta, pois o sucesso de um material é indicado por sua longevidade na cavidade oral e estudos clínicos devem ser desenvolvidos para verificação dos resultados.

\section{CONCLUSÕES}

Através da metodologia empregada e análise dos resultados, observou-se que:

1- As duas técnicas restauradoras (convencional e com hibridização) apresentaram microinfiltração marginal em diferentes graus, $\mathrm{e}$

2- Não houve diferença estatisticamente significante entre as duas técnicas.

\section{ABSTRACT}

This study evaluate the marginal microleakage in deciduous molars cavities restored with ionomer cement modified by resin (Vitremer, $3 \mathrm{M}$ ) comparing two different techniques: the conventional (according to manufacturer instructions) and with the hybridization technique (acid phosphoric $37 \%$ and adhesive system Scotchbond Multi Pourpose , 3M). Proximal cavities were prepared in 20 sound deciduous molars, right after extraction. The samples were randomly divided in two groups. Group 1 consisted in teeth prepared with the conventional technique and in the group 2 teeth with etching by phosphoric acid and adhesive system. The teeth were submitted to termical cycle process ( 100 cycles, each one of $3 \mathrm{sub}$ cycles of 5o C, 37o C and 55o C - by $60 \mathrm{Sec}$ of bath immersion each one), after restorations. After that, the teeth were impermeable with nail polish and wax \#7 keeping $2 \mathrm{~mm}$ of area in the junction of the cervical restoration margin, and them immersed in methylen blue solution to $0,5 \%$, seccionated and evaluated by one examiner, who established the microleakage degree. The data reveal the both techniques show the micro infiltration in different degree, but it has no statistical difference between techniques.

UNITERMS: Tooth, deciduous; Glass ionomer cements.

\section{REFERÊNCIAS}

1- Andersson-Wenckert IE, Folkesson UH, Van Dijken JW. Durability of a polyacid-modified composite resin(compomer) In primary molars. Acta Odontol Scand 1997 Aug; 55(4): 255-60.

2- Anusavice KJ. Phillips: materiais dentários. $10^{\mathrm{a}}$ ed. Rio de Janeiro: Guanabara Koogan; 1998. Cap. 5.

3- Carvalho RM. Ionômero de vidro. Maxi-Odonto: Dentística. 1995 Set/Out; 1(5) : 42.

4- Conceição EN. Aplicações clínicas dos materiais ionoméricos. In:__ Dentística: saúde e estética. Porto Alegre: Artmed; 2000. Cap. 10.

5- Conceição EN, Pires LAG, Pacheco JF. Avaliação clínica uso do ácido fosfórico como condicionamento de esmalte e dentina. Rev ABO Nac 1996 Abr/Mai; 4(2): 99-102.

6- Croll TP, Bar-Zion Y, Segura A, Donly KJ. Clinical performance of resin-modified glass ionomer cement restorations in primary teeth. J Amer Dent Assoc 2001; 132(8): 1110-6.

7- Dias GRS, Myaki SI, Rodrigues CRMD, Rodrigues Filho L, Ando T. Infiltração marginal em dentes decíduos restaurados com cimento de ionômero de vidro modificado por resina utilizandose a técnica convencional ou um sistema adesivo. J Bras Odontopediat Odontol Bebê 1999; 2 (10): 442-6.

8- Erickson RL. Surface interaction of dentin adhesive materials. Oper Dent 1992; Suppl 5: 81-94.

9- Espelid I, Tveit AB, Tomes KH, Alvheim H. Clinical behaviour of glass ionomer restorations in primary teeth. J Dent 1999 Aug; 27(6) :437-42.

10- Feilzer A J, De Gee Aj, Davidson CL. Curing contraction of composites and glass-ionomer cements. J Prosth Dent 1988 Mar; 59(3): 297-300.

11- Fritscher AMG, Araújo DF, Conceição EN, Pacheco JFM. Avaliação da infiltração marginal materiais ionoméricos em esmalte e dentina de dentes decíduos. J Bras Odontopediatr Odontol Bebê 2000; 3(12): 130-8.

12- Hickel RA, Folwaczny M. Various forms of glass ionomers and compomers. Oper Dent. 2001 Supl 6:177-90.

13- Hse KMY, Leung SK, Wei SHY. Resin ionomer restorative materials for children: a review. Aust Dent J. 1999; 44(1): 1-11.

14- Kramer PF, Pires LAG. Cáries incipientes: restaurar. In: Cardoso RJA, Gonçalves EAN. Dentística/Laser. São Paulo: Artes Médicas, 2002. p.133-49.

15- Kramer PF, Pires LAG, Longoni MB. Avaliação comparativa do grau de infiltração marginal entre duas técnicas restauradoras de inserção de resina composta em superfície proximal de molares decíduos. Rev ABO Nac 1999; 7(3) :152-5. 
16- Leal AMA . Avaliação comparativa in vitro da infiltração marginal em restaurações de dentes decíduos humanos com cimento ionômero de vidro modificado por resina, em função do tratamento do esmalte e da dentina. Araraquara; 1998. [Dissertação de Mestrado - Faculdade de Odontologia da Universidade Estadual Paulista].

17- Louguercio AD, Barbosa AN, Busato ALS, Barros A. Avaliação clínica de um ionômero de vidro modificado por resina poliácido modificada em lesões cervicais: acompanhamento de 02 anos. Rev Bras Odont. 2000 Jan/Fev; 57(1): 26-30.

18- Miranda Jr. WG. Avaliação da infiltração "in vitro"em caixas proximais restauradas com resinas compostas e cimento de ionômero de vidro. São Paulo; 1992. [Dissertação Mestrado Faculdade de Odontologia da Universidade de São Paulo].

19- Morabito A, Defabians P. The marginal seal of various restorative materials in primary molars. J Clin Ped Dent. 1997 Fall; 22 (1): 51-4.

20- Nakabayashi N, Kojima K, Masuhara E. The promotion of adhesion by infiltration of monomers into tooth substrates. $\mathrm{J}$ Biomed Mat Res 1982; 16(3): 265-73.

21- Rino, MLM, Myaki SI, Miranda Jr. WG, Ando T. Avaliação in vitro da infiltração marginal nas cavidades proximais de molares decíduos restaurados com cimento de ionômero de vidro modificado por resina, utilizando-se dois diferentes procedimentos restauradores. Rev Bras Odontol 1998 Nov/Dez; 55(6): 318-21.

22- Rodrigues CC. Microinfiltração em resturações de cimentos ionômeros de vidro utilizando duas técnicas restauradoras. In: Anais da $17^{\text {a }}$ Reunião Anual da Sociedade Brasileira de Pesquisa Odontológica; 2000, 3-6 set.; Águas de Lindóia (SP). São Paulo : $\mathrm{SBPqO} ; 2000$, v.14, p.184, resumo AO76.

23- Sidhu SK, Watson TF. Resin-modified glass ionomer materials.A status for the American Journal of Dentistry. Am J Dent 1995; 8(1): 59-67.

24- Silveira DL, Ulian J, Louguercio AD, Camacho GB, Barbosa NA, Busato ALS. Avaliação de microinfiltração in vitro em restaurações com Vitremer (3M) associado ou não com a camada híbrida. Rev Bras Odontol 1999 Nov/Dez; 56(6): 268-72.

25- Souza Jr MH. Adesivos dentinários: evolução, estágio atual e considerações clínicas para sua utilização. Maxi-Odonto: Dentística 1995 Jan; 1(1):1-18.

26- Swift Jr EJ , Vann Jr WF. Restauration of primary molars using a new "compomer" material. Pract Periodontics Aesthet Dent. 1995 Oct; 7(8): 25-30.

27- Toledano M, Osorio E, Osorio R, Garcia-Godoy F. Microleakage of class $\mathrm{V}$ resin-modified glass ionomer and compomer restorations. J Prosth Dent 1999 May; 81(5):610-5.

28- Yap A, Lim CC, Neo JC. Marginal sealing ability of three cervical systems. Quintessence Int 1995 Nov; 26 (11): 817-20.
Recebido para publicação em: 12/11/ 2002

Aceito após reformulações em: 13/03/2003

Endereço do autor correspondente:

Paulo Floriani Kramer

Rua 24 de Outubro, 435 Conj. 307

CEP: 90510-002

Porto Alegre-RS

E-mail: paulokramer@hotmail.com 